Ginevicius, R. (2019). Quantitative Assessment of the Compatibility of the Development of

Socioeconomic Systems. Journal of Competitiveness, 11(2), 36-50. https://doi.org/10.7441/joc.2019.02.03

\title{
QUANTITATIVE ASSESSMENT OF THE COMPATIBILITY OF THE DEVELOPMENT OF SOCIOECONOMIC SYSTEMS
}

\section{- Romualdas Ginevicius}

\begin{abstract}
In the conditions of market economy all business entities, which can be viewed as socio-economic systems (SES), must be competitive. This also applies to the regions in the country. From the regions competitiveness depends effective solving of a whole range of social problems: jobs, social welfare, crime, migration and etc., in turn country region's competitiveness depends on how it is adjusted its economic, social and ecological development. It's important because it could be that some of the development components are developing at other component's expenses. For example, economic development could be at social and ecological expenses. This would prevent the creation of the necessary living conditions not only today, but also for future generations.

In order to survive, an SES must be constantly developing. During this development, both quantitative and the qualitative changes of the system parameters take place. The quantitative changes are reflected by the development dynamics, which encompass the equability and the intensity; while the qualitative changes are reflected by changes in the internal structure of the development process. For a system to be able to function in the long term, the quantitative development of its components must be mutually compatible. However, the existing measurements of SES development do not take this into account.

The aim of the article is to propose and approve a methodology that would allow quantitatively evaluate the sustainability of the country regions development. For this purpose the multi-criteria evaluation methods are used. Based on the proposed methodology the sustainability of the country regions economic development is identified.
\end{abstract}

Keywords: socioeconomic system development, sustainable development, quantitative assessment of compatibility in socioeconomic system development

JEL Classification: Q01

Received: December, 2018

1st Revision: May, 2019

Accepted: May, 2019

\section{INTRODUCTION}

Despite the fact that sustainable development (SD) has been one of the most relevant problems for humanity over the past 30 years, and is a topic that has been analysed in many various ways, 
some of the key issues still remain unresolved. One of these is the quantitative assessment of the achieved SD level. Due to the complexity of the SD phenomenon, a myriad of systems aimed at evaluating it have appeared. Today, there are over 500 SD indicator models: around 70 of them are global, over 100 national, over 70 regional, and around 300 are local (Paris \& Kates, 2003; Debnath et al., 2018). An analysis of these models shows that each of the indices or their systems is designed to assess the state of the SD development from a certain aspect - economic, environmental, etc. All of this indicates that we have not yet fully understood the SD phenomenon itself: its origin, internal structure, development mechanisms, etc.

A precondition of socioeconomic systems is their continual development. This is a natural feature in any formation of a living being, from biological ones to an SES. This is the case because all of these systems are open, i.e. they are determined by their environment. There is a constant exchange between the SES and its environment. The system performs certain functions for the benefit of its environment, and in return for carrying out this mission it receives from the environment the resources necessary for it to function (people, information, materials, etc.). At a lower level, in such an exchange process the system must constantly adapt to the environmental requirements. This is a precondition for its survival. The general trend is that the environmental needs constantly grow, so the scale of the system's development must exceed the scale of the environment's development in order for the system to survive.

The result of the SES development is, first of all, quantitative changes to its parameters: the quantities of the production, services, etc. On the other hand, it is insufficient for an SES to increase its functions in the context of the environment only in terms of the quantity; e.g., for a car company, simply supplying a sufficient amount of cars to the market is not the only important aspect. The qualitative requirements - the appearance, convenience, efficiency, durability, etc. - are equally important. Therefore, the issue of the quality of the SES development process must be taken into account. The quantity and quality of the development are equivalent to the two sides of any process. Without a sufficient quantity, there is no quality, and vice versa.

The quantitative aspect of the SES development is reflected by its dynamics, which indicate the scale and types of the development processes that take place within an analysed period.

Conversely, the qualitative side of SES development is reflected by the changes in its structure. It plays a special role in the development process. A structure is a precondition of the system's stability. It shows which things in the system remain unchanged during various external and internal changes. The SES development process needs a structure as a framework to provide its components with the necessary force, integrity and orientation, as well as the possibility to achieve the development's goals. The structural changes in the development process, which arise due to the effect of destabilising factors, imply the existence of an SES development process structure that is characteristic of the SD and the existence of a structure which reflects the actual state of the development. Even when the SES is developing dynamically and sustainably, the development goals may not be achieved due to an inappropriate structure of the development process; e.g. the environmental goals may be missed if the economic development is occurring at the expense of the environment. Therefore, the indicator reflecting the qualitative side of the SES development process should be considered in terms of its compatibility. 
The SES development process can be divided into two parts: the development dynamics or sustainability; and the development's compatibility. The first part signifies the stability and equability of the process, while the second part reflects the compatibility of the components in the development process. The quantitative assessment of both the sustainability and the compatibility can be based on the actual state of the SES development. Therefore, the first stage of the quantitative assessment of the SES development is to determine the state of the SD (Ginevičius et al., 2018; Bilan et al., 2019).

Currently, the quantitative assessment of the SES development in terms of the SD is gaining special relevance in both theory and practice. Without knowing the achieved SD level of the development process, it is impossible to purposefully control it and to determine whether the SD goals have been achieved. It is also difficult to understand whether the development is occurring sustainably, i.e. whether, for instance, the economic development is occurring at the expense of the environment, social development, etc.

\section{OVERVIEW OF THE ASSESSMENT METHODS FOR THE SUSTAINABLE DEVELOPMENT OF SOCIOECONOMIC SYS- TEMS}

In the existing situation, a quantitative assessment of the SES development compatibility can be determined only in the context of a general SD measurement; therefore, it is useful to review the current SD assessment methods.

First of all, in order to evaluate the existing SD indicators, indices or their systems, a more indepth look into the origin, internal composition, development mechanisms and other aspects of this phenomenon is needed.

It has been determined that it is logical to divide the SD into two parts: the quantitative and qualitative aspects (Ginevičius et al., 2018). The quantitative part of the SES development (its compatibility) is reflected by its dynamics. International dictionaries define this as a stable, constant and evenly developing process. The necessity for sustainable development is predetermined by the fact that, being an open system, the SES must adapt to the constantly changing conditions in its surrounding environment (i.e. it must develop) in order to survive in the long term. Based on this, the sustainability of any SES development can be defined as constantly occurring quantitative changes in the parameters of a socioeconomic system which ensure it will continue operating over the long term. Of course, the SES development can also be negative but still sustainable.

The SES quantitative development process itself can be further divided into its quantitative and qualitative aspects. The first is reflected by the scale of the positive/negative changes to the development during an analysed period; while the second aspect is reflected by the type or equability of a particular process. In order to determine an indicator of the sustainability of the SES development, both of these aspects have to be combined into a single joint value. Based on this methodology, defined as MDD, the sustainability of the economic development of some EU countries has been evaluated (Ginevičius et al., 2018). 
A more difficult task is to quantitatively assess the qualitative side of the SES development, i.e. its compatibility. This requires a systematic approach to the surrounding environment. Three types of systems can be singled out within the environment: technical, biological and social. The first type differs from the other two, in that it is a non-living system and as a result it does not develop over time.

The biological and social systems (and the socioeconomic systems based on the social ones) have a living nature, thus they develop over time. This is their inherent feature, just like growing is inherent to humans. The question then is: What are the conditions necessary for the functioning and development of these systems.

A human being is the most perfect biological system. It can function and grow only if three key preconditions are met: he/she must be able to breath, consume water and food. Air supplies the body with oxygen, while water is necessary for the body's cells, and food provides the human being with energy. In order for the human body to function, grow and be healthy, it needs to receive the three resources not only in the right amounts, but also in certain proportions. It has been measured that the human body can survive without food for approximately 40 days, without water for approximately 7 days, and without air for 0.0021 days, i.e. approximately 3 minutes. What happens when these proportions become distorted? If a human organism breathes improper air, consumes too little water (a problem that is widely discussed these days) or eats too little (as is the case in some African countries), the body exhausts itself, it ages more quickly, it becomes less resistant to diseases, etc. Then, the sustainable development of the body is unlikely.

What conclusions can we draw from this example, in terms of the SES sustainable development issue? Firstly, any living system in nature, including the SES, has typical key components without which it cannot exist. This is an objective precondition for the existence and functioning of such systems. Secondly, the development of the entire system is impossible without the development of its separate components. Thirdly, for a system to be able to function in the long term, the development of these components must be mutually compatible. We can now look at the degree to which the proposed SES SD indicators correspond to the above conclusions.

First of all, it should be noted that there have not been many systematic research studies aimed at analysing the assumptions and issues involved in SD assessments. The circumstances for such research are unfavourable due to the non-systematic analysis of the SD phenomenon. The main factors that have hindered the resolution of the issue of the quantitative assessment of SD as a complex process, for the purposes of its effective control, are the inflexibility and inadequacy of the assessment systems used to understand the SD phenomenon. There is a lack of systematic research that has analysed the individual components of this issue in an integrated way.

Maybe this is the reason why there are disagreements concerning the contents of SD, irrespective of the fact that most researchers define it in a similar way. It is often said that it is difficult to understand what the SD process actually means in practice; that its manifestations are unknown; that it is difficult to describe, etc. (Šaparauskas, 2004; Alberti \& Susskind, 1996; Campagni et al., 1998).

On the other hand, many studies can be found that highlight the key features of SD. First of all, sustainable development is the structure of the SES development process. The point of the 
current discussions is to establish what components should be included in the SD model, and to what extent. The number of components to be included was described in the three-pillar theory proposed by John Elkington in 1990 (Elkington, 1998). To date, this remains the basic framework for measuring the results of SES operations. According to this theory, the success of an organisation should be assessed using three parameters: social, economic and environmental. Similarly, the United Nations' understanding of SD is based on the same three components, which are given an equal value (Burton, 1987; Freymann, 2012). Most researchers recognise the system of the three SD components as acceptable and the best method of reflecting the interactions between systems (Lozano, 2008; Thompson, 2007; Roseland, 2000; Smit \& Smithers, 1993; Epstein et al., 2015; Elzen et al., 2017; Abdi et al., 2018; Ciobanu, et al., 2019; Nastiti et al., 2019). With the recognition that the principle structure of the SES process consists of the above three components, the scientific literature includes extensive analyses focused on the proportions of these components in the development process. In other words, researchers have analysed the attributes of the SD of SES. Except for minor variations, their opinions have been unanimous. The attributes are: equilibrium must exist between the economic, social development and pollution (Barredo \& Domicheli, 2003); there must be a state of a dynamic equilibrium where the aim is to maintain a long-term internal equilibrium between the economic, social and environmental components (A Framework ... 2003); compatibility of the SD components is a precondition for long-term equilibrium (Šaparauskas, 2004); there must be internal compatibility of the SES development process, as well as internal equilibrium (Ravetz, 2004); a harmonious combination of the economic, social and environmental factors is needed (Rajnoha \& Lesníková, 2016; Holden et al., 2017; Ivanová \& Čepel, 2018; Marikina, 2018); there are interactions and balances among the three key SD dimensions (Volkov 2018); the combination of the three SD components creates an internal equilibrium (Burinskiené, 2003; Barredo \& Domichelli, 2003; Yoon \& Lee, 2003; Piorr et al., 2009); and a state that must be maintained for an unlimited time without the loss of quality (Alberti \& Susskind, 1996). Therefore, one key attribute can be noted, which is mentioned in all the above cases: an internal equilibrium, or compatibility, of the SES development components is required.

Based on the views provided above, this compatibility can be defined as follows. It is a mutually synchronised development of the key SES development components that comprise the preconditions for achieving the system's goals.

After analysing the scientific literature, the conclusion can be made that the SD indicators of the SES have to integrate both the quantitative and the qualitative sides of the development, i.e. the intensity, equability and compatibility of the key components should be assessed.

The global development goals set by our society, including the modern realities and future expectations, can only be achieved if there is a possibility to control the SD process. The extent to which these goals are achieved can be measured by the SD indices, which combine the indicators formed on the basis of the primary sources of information. Therefore, with regard to the SD issues, researchers should use not the indicators themselves but the indices that reflect the SD process in various aspects and at various levels of integration.

Such research can be divided into two main trends: the first involves the quantitative assessment of the development of the individual SD components; while the second is the same type of as- 
sessment of the entire SES. The first approach combines the partial indices that reflect aspects of the development of the key development components - economic, social and environmental; whereas the other approach attempts to combine the key development components into a single joint value.

The aim of the economic development indices is to measure and compare the benefits and costs of economic growth. For this purpose, several aggregate indices have been proposed including the Index of Sustainable Economic Welfare (JSEW), Genuine Progress Indicator (GPI) and the Sustainable Net benefit Index (SNBI).

Meanwhile, the Human Wellbeing Index (HWI) the Human Development Index (HDI) (McGillivray, 1990) can be regarded as social development indices.

There are a great many environmental indices, of various sorts. Among them, the UNSTAT model covering 72 indices (Scherp, 1994) is noteworthy. There have also been many specialised indices proposed that can create an aggregate value for the state of the component in the development of individual human activities, such as agriculture (Volkov, 2018), urban development (Činčikaitè, 2014) and others.

Various countries use different SD index systems. For example, in Germany the SD monitoring system is based on 218 indices, in France 132, in Finland 88, and in Switzerland 120 indices. Both individual scientists and groups have been working to develop their approach to an integrated complex assessment of the SD components (Priori, 2003; Gomiero et al., 2011; Sydorovych \& Wossink, 2008; Slätmo et al., 2017 and others).

After some time, the researchers reached the opinion that an assessment of the development of individual components does not allow for control of the entire SD and can hinder the achievement of some set goals. As a result, there have been attempts to combine the indices that assess the state of the individual SES components into a single complex criterion. However, this type of research is not very common. The proposals include an integrated assessment of the SD of a country's regions, an integrated assessment of the SD of the common agricultural policy (Common Agricultural Policy-CAP) (Piorr et al., 2009), and an assessment of the direct payment system on the SD in agriculture (Volkov, 2018). In all of the above cases, it has been emphasised that all the three SD components (economic, social and environmental) are of equal value.

To summarise, the proposed approaches to the quantitative assessment of the SD of an SES do not meet the requirements applicable for such assessments, because they do not take into account the intensity and equability of the development process. Furthermore, they do not consider the internal compatibility of the development components. The most common opinion is that, if the changes to all three SD components are positive, this means that the development is occurring in a sustainable way (Volkov, 2018). However, in reality, this is merely an assessment of the state of the SES development at different complexity levels during an analysed period, whereas the aim of determining the effectiveness of the SD concept raises the issue of its adequate measuring, because the SD strategies lack a solid scientific basis without a quantitative framework. The conclusion can be made that the qualitative side of the socioeconomic system development is currently not being assessed in terms of the quantity, because no way of measuring this has been proposed before now. 


\section{PROPOSED METHOD FOR A QUANTITATIVE ASSESS- MENT OF THE SUSTAINABLE DEVELOPMENT OF SOCIO- ECONOMIC SYSTEMS}

Before proposing a SES development compatibility index, we should look at the requirements that should apply to it. It has been said that, when creating quantitative SD measurements, certain things should be clearly indicated, including: what aspects of the compatibility are to be assessed, which of them are to be maintained and developed, and how these different aspects should be related to one another and interpreted (Wilson \& Wu, 2017). Another important finding is that the SD indicators must be analysed and interpreted as a distance to the desired target (Wass et al., 2014). Almost all of the existing studies emphasise the fact that the economic, social and environmental factors should be of equal value and combined harmoniously (Lozano, 2008; Holden et al., 2017; Marghescu, 2005). Also, the assessment should include not only the individual parts of the analysed process but also the relationships between them (Gibson et al., 2005; Gomiero et al., 2011).

According to the above-mentioned criteria, the following preconditions necessary for the desired SES development compatibility indicator can be formulated:

1. According to Brutland's definition, SD is understood as a compromise between the environmental, economic and social goals, while enabling the society to meet the needs of both existing and future generations. A question therefore arises concerning how to integrate this compromise into the model for the quantitative assessment of the SD. It could be assumed that such a possibility will appear if all the three SD components - economic, environmental and social - are regarded as equal, i.e. equally important in terms of the SD. However, in this case, it remains unclear how the social and environmental components can be combined with the economic one, i.e. with the main business goal, which is to earn a profit from the business. In other words, the problem of how to account for the fact that the basis for SES development is economic development, which requires that the business entities earn a profit, remains.

2. The indicator has to take into account the level of the internal compatibility of the SD components (economic, social and environmental).

3. The SD indicators and indices should be analysed and interpreted as a distance to the desired target (Wass et al., 2014).

We have to fully agree with the assertion that economic development is at the heart of the SES development. On the other hand, giving a special role to this component of the SES development does not imply that one component is opposed to the others, nor does it represent a retreat from the universally-accepted view that they are all equal in terms of the SD. Everything falls into place if we remember the definition of SD. There are two fundamental aspects to SD: firstly, human development must meet the current needs of the society; and secondly, the possibilities for future generations to meet their own needs should not be reduced. What is required to fulfil these two conditions?

In order to ensure the social well-being of people today, the economy must develop. However, in order not to reduce the possibilities for future generations to meet their own needs, the economy 
must not develop at the expense of the environment. Therefore, both of these circumstances - the equal value of all the three SES SD components, as well as the priority applied to the economic development compared to the other two components - need to be integrated into the SD model.

In order to take into account, the second assumption, it is necessary to determine the state of the SES development components that correspond to the SD model, as well as their actual state. In this case, the deviation of the $\mathrm{j}$-th component from its value corresponding to the SD model will be shown by the following difference:

$\Delta D_{j}^{T}=K_{D}^{T}-K_{j}^{T}$

where $\Delta D_{j}^{T}$ is the deviation of the actual development of the $\mathrm{j}$-th component of the SES from the sustainable development model during the analysed period T; $K_{D}^{T}$ is the value of each SES development component during the analysed period T (in a particular year), corresponding to the SD model; $K_{j}^{T}$ is the value of the actual development of the $j$-th component of the SES during the same period; and, $j=\overline{1, m}, \mathrm{~m}$ is the number of SES components.

The level of the compatibility of the entire SES development process can be calculated by adding the absolute values of the deviations of all the components:

$D_{T}=\sum_{j=1}^{m}\left|\Delta D_{j}^{T}\right|=\sum_{j=1}^{m}\left|K_{D}^{T}-K_{j}^{T}\right|$

where $D_{T}$ is the scale of the deviations of the actual development from the SD model $K_{D}^{T}$ during the analysed period $\mathrm{T}$.

When $K_{D}^{T}=K_{j}^{T}$, i.e. ideally, $\Delta D^{T}$ should be at the highest value; however, the formula (2) implies that in this case, it would be equal to 0 . To avoid this, the value $\Delta D^{T}$ should be subtracted from one. Therefore, the final formula for the quantitative assessment of the SES development compatibility will be as follows:

$S D^{T}=1-\sum_{j=1}^{m}\left|K_{D}^{T}-K_{j}^{T}\right|$

where $S D^{T}$ is the indicator of the SES development compatibility during the analysed period T. In the formula (3), the problem is solved by finding the values $K_{D}^{T}$ and $K_{j}^{T}$.

As was mentioned above, the first stage in the quantitative assessment of sustainable development is the determination of the actual state of development of the SES components. Socioeconomic systems are large and complex, and will manifest in many different aspects in reality. The key to assessing the actual state of their development is the formation of an adequate system of indicators. This situation is complicated by the fact that their impact on the analysed phenomenon is different, so each indicator should be expressed by two values - its importance and its significance. The importance is determined by experts, although the adequacy of the expert judgment depends on the number of indicators. It is believed that an expert can adequately assess the importance of 10-12 indicators (Ginevičius et al., 2016). 
If this figure is not exceeded, a single-level system of indicators reflecting the SES development can be developed. Nonetheless, the number of indicators that actually reflect such complex systems is much higher. For example, the economic-social development of the country's regions is reflected by dozens of different indicators. In order to reduce the number of indicators to be assessed at the same time, a hierarchically-structured system of indicators is formed, i.e. the related indicators are grouped together. For example, indicators reflecting the economic-social development of the country's regions are usually grouped together according to its key economic, social and environmental aspects (Ginevičius, 2009).

The indicators reflecting the SES development can be expressed in different dimensions, as their changes may occur in opposite directions, i.e. an increase in the values of one group of indicators may improve the development situation, while an increase the values of other indicators may worsen it. In order to quantitatively assess the state of the SES development, all of the indicators have to be combined into a single joint value. Multi-criteria methods have recently been widely used to find the solutions to such problems. Their philosophy is reflected by the SAW method, which is the basis on which all the other methods of multi-criteria assessment were developed.

The expression of the SAW method is as follows (Hwang \& Yoon 1981):

$$
K=\sum_{i=1}^{n} w_{i} \widetilde{q}_{i}
$$

where $K$ is the criterion of the SAW method; $w_{i}$ is the importance of the $\mathrm{i}$-th indicator, $\left(\sum_{i=1}^{n}=1,0 ; \overline{1, n}, \mathrm{n}\right.$ is the number of indicators); and $\widetilde{q}_{i}$ is the normalised value of the $\mathrm{i}$-th indicator.

In terms of the issue being analysed here, concerning the SES development compatibility, it is important to define the values for the multi-criteria assessment of the components (economic, social and environmental). This is made possible by combining all the indicators reflecting the SES development into groups of indicators that reflect the components. In this case, based on formula (1), the value of the multi-criteria assessment of the $j$-th component of the SES development will be determined as follows:

$\widetilde{K}_{j}^{T}=\sum_{i=1}^{n} w_{i j} \widetilde{q}_{i j}$

where $\widetilde{K}_{j}^{T}$ is the value of the multi-criteria assessment of the $\mathrm{j}$-th component (economic, social, environmental) of the SES development during the analysed period T; $w_{i j}$ is the importance of the $\mathrm{i}$-th indicator of the SES development component; and $\widetilde{q}_{i j}$ is the normalised value of the i-th indicator of the SES development component.

In order to determine the development state of the entire SES, the importance of its various components (economic, social, environmental) must be assessed. This can be established on the basis of the first precondition of $\mathrm{SD}$, which states that the current living conditions of humanity must be ensured. This aim can be achieved if the economic development, which is the basis of the SES development, is given a higher weight when compared to the other components. In this case, based on formula (4), the actual state of the development of the $j$-th component of the SES will be determined as follows: 
$K_{j}^{T}=\widetilde{w}_{j} \widetilde{K}_{j}^{T}$

where $K_{j}^{T}$ is a criterion of the actual state of the SES development during the period T; and $\widetilde{w}_{j}$ is the importance of the $\mathrm{j}$-th component of the SES development.

Another value $K_{D}^{T}$ of formula (3) reflects a certain state of the SES development components. Therefore, it must also rely on assessments of their actual state. On the other hand, these values must be transformed in such a way so as to conform to the SES development compatibility model (3).

The literature analysing the SD unanimously claims that all the three components (economic, social and ecological) of the SES are equally important (Volkov, 2018; Piorr et al., 2009; Wilson and Wu,2012; Wass et al., 2014; Lozano, 2008); Holden et al., 2017; Marybesus, 2005). In this case, the proportions of their values will be determined as follows:

$\frac{\widetilde{w}_{d 1}}{\widetilde{w}_{d 2}}: \frac{\widetilde{w}_{d 2}}{\widetilde{w}_{d 3}}: \frac{\widetilde{w}_{d 2}}{\widetilde{w}_{d 3}}=1: 1: 1$

where $\widetilde{w}_{d 1}, \widetilde{w}_{d 2}, \widetilde{w}_{d 3}$ are the weights of the SES development components (economic, social and environmental) in the SD model.

The values of the components calculated using multi-criteria assessments are variable because the SES is constantly evolving. However, we need to determine whether this development is sustainable, i.e. whether the components of the development are taking place in a coordinated manner. This will be the case if, by multiplying the component weights by their values, we get the same proportions of these multiplications as the proportions of the initial weights. This is what we will get if the normalised values of all the components of the SES development are equal, i.e. Then, similarly to the case of formula (7), we get:

$\frac{\widetilde{K}_{1}^{T}}{\widetilde{K}_{2}^{T}}: \frac{\widetilde{K}_{1}^{T}}{\widetilde{K}_{3}^{T}}: \frac{\widetilde{K}_{2}^{T}}{\widetilde{K}_{3}^{T}}=1: 1: 1$

which means that $\widetilde{w}_{d 1} \widetilde{K}_{1}^{T}: \widetilde{w}_{d 2} \widetilde{K}_{2}^{T} \widetilde{w}_{d 3} \widetilde{K}_{3}^{T}=1: 1: 1$.

It should be remembered that the values of all the three components have been normalised, i.e. the format of their variation is the same, irrespective of their absolute values and dimensions, and it ranges from 0 to 1 . This circumstance means that the value of the development of the SES components conforms to the SD idea, i.e. it does not violate the determined proportions (5-7), and can be equated to the average of all their normalised values:

$\overline{\widetilde{K}}^{T}=\frac{\widetilde{K}_{1}^{T}+\widetilde{K}_{2}^{T}+\ldots+\widetilde{K}_{m}^{T}}{m}=\sum_{j=1}^{m} \frac{\bar{K}_{j}^{T}}{m}$

where $\overline{\widetilde{K}}^{T}$ is the average of the normalised values of the SES components (in our case $\mathrm{m}=3$ ).

The value $\bar{K}_{j}^{T}$ is the transformed value of the $j$-th component of the SES development, corresponding to the SES development SD model (3). From formula (3), it can be seen that $\bar{K}_{j}^{T}=\bar{K}_{j+1}^{T}$ 
In order to determine the final value of the development of the $j$-th component of the SES in accordance with the SD model, the value $\widetilde{K}^{T}$ must be multiplied by the weight of the j-th component in accordance with the SD model (3): $\widetilde{w}_{d j}=\widetilde{w}_{i=d j+1}$, tai $\widetilde{w}_{d j}=\frac{1}{m}$. Then, the value of each development component during the analysed period $\mathrm{T}$, in accordance with the SD idea, will be equal to:

$$
K_{D}^{T}=\frac{\overline{\widetilde{K}}^{T}}{m}
$$

In this case, according to formula (3), we get:

$D^{T}=1-\sum_{j=1}^{m}\left|\widetilde{w}_{d j} \frac{\sum_{j=1}^{m} \widetilde{K}_{j}^{T}}{m}-\widetilde{w}_{j} \widetilde{K}_{j}^{T}\right|=1-\sum_{j=1}^{m}\left|\frac{\sum_{j=1}^{m} \widetilde{K}_{j}^{T}}{m^{2}}-\widetilde{w}_{j} \widetilde{K}_{j}^{T}\right|$

According to the formulas (3, 6, 9 and 10), we can find the final expression of the quantitative assessment of the SES development compatibility during the analysed period $\mathrm{T}$ :

$$
D^{T}=1-\sum_{j=1}^{m}\left|\frac{\overline{\widetilde{K}}^{T}}{m}-\widetilde{w}_{j} \widetilde{K}_{j}^{T}\right|=1-\sum_{i=1}^{m}\left|K_{D}^{T}-K_{j}^{T}\right|
$$

The suitability of the proposed SES development compatibility index will be verified by a real example. According to a multi-criteria assessment using the SAW method, the following values of the economic development of one of the regions of Lithuania were found (Table 1).

Tab. 1. - Results of a multi-criteria assessment of the state of the components of the economic development of the Vilnius region of the Republic of Lithuania for 2017

\begin{tabular}{|l|l|l|l|l|l|l|l|l|}
\hline $\begin{array}{l}\text { Economic devel- } \\
\text { opment compo- } \\
\text { nents }\end{array}$ & \multicolumn{2}{|l|}{ Industry } & \multicolumn{2}{l|}{ Construction } & \multicolumn{2}{l|}{ Agriculture } & \multicolumn{2}{l}{ Transport } \\
\hline & value & weight & value & weight & value & weight & value & weight \\
\hline $\begin{array}{l}\text { Multi-criteria as- } \\
\text { sessment value }\end{array}$ & 0.3858 & 0.3 & 0.5287 & 0.22 & 0.1642 & 0.28 & 0.5318 & 0.2 \\
\hline
\end{tabular}

According to Table 1 and Formula 12, we will determine the economic development compatibility index as follows:

$K_{D}^{17}=1-\left(\left|\frac{0.4026}{4}-0.1157\right|+\left|\frac{0.4026}{4}-0.1163\right|+\left|\frac{0.4026}{4}-0.0460\right|+\left|\frac{0.4026}{4}-0.1064\right|\right)=$

$1-(0.0151+0.0157+0.0547+0.0058)=0.91$

The result shows a very high degree of compatibility in the region's economic development. The main reason for this may be that the region includes Vilnius, the country's capital. On the other hand, the industry, construction and transport components are developing faster than agriculture, i.e. their development occurs at the expense of agriculture. 


\section{CONCLUSIONS}

One of the most important unresolved problems in the sustainable development of socioeconomic systems is the possibility of reaching a quantitative assessment. Basically, the indicators, indices or their systems, which are used today, do not quantitatively assess the sustainable development of the individual aspects of the SES development, the components that combine these aspects, or the system as a whole. They only assess the actual state of the development. This is because the SD phenomenon has not yet been fully understood.

During the SES development process, both quantitative and the qualitative changes take place in its parameters. The quantitative changes reflect the dynamics of the process, which includes the equability and intensity of the development; while the qualitative changes reflect the changes taking place in the internal structure of the processes. In order for the system to function successfully in the long term, the development of the key elements of its structure, or the components (economic, social and environmental), must be mutually combined. Therefore, in order to quantitatively assess the SD, it must be possible to assess the sustainability (the quantitative side) and the compatibility (the qualitative side) of the development.

The proposed method for the quantitative assessment of the SES qualitative development, or its compatibility, satisfies the key premise for the formation of this index: it considers economic development as the basis for the SES development, but at the same time values all the three components of the SD model equally; it evaluates the compatibility level of these components; and it determines the distance between the actual state of the development and the state that corresponds to the SD.

This method for the quantitative assessment of compatibility in the SES development is universal. It can be used to determine the internal compatibility of the development of various levels and types of processes. The performed calculations have confirmed its suitability for practical applications.

In order to quantitatively assess the SES sustainable development in its entirety, the development sustainability and compatibility indices have to be appropriately combined into a single composite index.

\section{References}

1. Abdi, K., Mardani, A., Senin, A., Tupenaite, L., Naimaviciene, J., Kanapeckiene, L., \& Kutut, V. (2018). The effect of knowledge management, organizational culture and organizational learning on innovation in automotive industry. Journal of Business Economics and Management, 19(1), 1-19. https://doi.org/10.3846/jbem.2018.1477.

2. Alberti M., \& Susskind L. (1996). Managing urban sustainability: An introduction to the special issue. Environmental Impact Assessment Review, 16(4-6), 213-221.

3. Androniceanu, A. (2017). Hospital management based on the relationship between doctors and patients. Administratie si Management Public, 29, 41-53.

4. Barredo J. I., \& Domicheli, L. (2003). Urban sustainability in developing countries' megacities: modelling and predicting future urban growth in Lagos. Cities, 20(5), 297-310. 
5. Bilan, Y., Vasilyeva, T., Lyeonov, S., \& Bagmet, K. (2019). Institutional complementarity for social and economic development. Business: Theory and Practice, 20, 103-115. https://doi. org/10.3846/btp.2019.10.

6. Burinskiene, M. (2003). Subalansuota miestu pletra. Monografija. Vilnius: Technika. 252.

7. Burton, I. (1987). Report on reports: Our common future: The world commission on environment and development. Environment: Science and Policy for Sustainable Development, 29(5), $25-29$.

8. Campagni R., Capello R., \& Nijkamp P. (1998). Towards sustainable city policy: an economy- environment technology nexus. Ecological Economics, 24(1), 103-118.

9. Ciobanu, A, Androniceanu, A, \& Lazaroiu, G. (2019). An integrated psycho-sociological perspective on public employees' motivation and performance. Frontiers in Psychology, 10(36). https://doi: 10.3389/fpsyg.2019.00036

10. Činčikaitè, R. (2014). The measurement of urban competitiveness in a complex way on the perspective of sustainable development. Doctoral thesis. Vilnius. 155.

11. Debnath, A., Bandyopadhyay, A., Roy, J., \& Kar, S. (2018). Game theory based multi criteria decision making problem under uncertainty: a case study on Indian Tea Industry. Journal of Business Economics and Management, 19(1), 154-175. https://doi.org/10.3846/1611169 9.2017.1401553.

12. Elkington, J. (1998). Cannibals with forks: The triple bottom line of 21st century business. Gabriola Island, BC Canada: New Society Publishers.

13. Elzen, B., Janssen, A. P. H. M., \& Bos, A. P. (2017). Portfolio of promises: Designing and testing a new tool to stimulate transition towards sustainable agriculture. AgroEcological Transitions, 143-161.

14. Epstein, M. J., Buhovac, A. R., \& Yuthas, K. (2015). Managing social, environmental and financial performance simultaneously. Long Range Planning, 48(1), 35-45.

15. Freyman, M. (2012). An Exploration of Sustainability and its Application to Corporate Reporting. Retrieved February 15, 2019, from http://iri.hks.harvard.edu/files/iri/files/an-explorationof-sustainability- and-its-application-to-corporate-reporting.pdf.

16. Gibson, R., Hassan, S., Holtz, S., Tansey, J., \& Whitelaw, G. (2005). Sustainability Assessment: Criteria. Processes and Applications. London: Earthscan.

17. Ginevičius, R., Gedvilaitè, D., Stasiukynas, A., \& Šliogerienè, J. (2018). Quantitative assessment of the dynamics of the economic development of socioeconomic systems based on the MDD method. Inžinerine ekonomika = Engineering economics, 29(3), 531-532.

18. Gomiero, T., Pimentel D., \& Paoletti, M. (2011). Is There a Need for a More Sustainable Agriculture? Critical Reviews in Plant Sciences, 30(1-2), 6-23.

19. Grabara, J. (2019). Sustainable development - Never fulfilled dream. Quality - Access to Success, 20 (1), 565-570.

20. Holden, E., Linnerud, K., \& Banister, D. (2017). The imperatives of sustainable development. Sustainable Development, 25(3), 213-226. 
21. Hwang, C. L., Yoon, K. (1981). Multiple Attribute Decision Making Methods and Applications. Berlin: Springer-Verlag.

22. Ivanová, E., \& Čepel, M. (2018). The Impact of Innovation Performance on the Competitiveness of the Visegrad 4 Conutries. Journal of Competitiveness, 10 (1), 54-72. https:// doi.org/10.7441/joc.2018.01.04

23. Koziuk, V., Dluhopolskyi, O., Farion, A., \& Dluhopolska, T. (2018). Crony Sectors as a Barrier to Economic Well-Being and Ecologization (Case of Ukraine). Economics and Sociology, 11(3), 113-132. https://doi.org/10.14254/2071-789X.2018/11-3/7

24. Lozano, R. 2008. Envisioning sustainability three-dimensionally. Journal of Cleaner Production, 16(17), 1838-1846.

25. Marikina, M. (2018). The Impact of Ecological Regulations and Management on National Competitiveness in the Balkan States. Journal of Competitiveness, 10(4), 120-135. https://doi. org/10.7441/ joc.2018.04.08

26. Marghescu, T. (2005). Greening the Lisbon Agenda?=Greenwashing? In Presentations at the Greening of The Lisbon Agenda Conference, EPSD. 23 February, unpublished. Strasbourg: European Parliament.

27. Mishchuk, H., Samoliuk, N., Bilan, Y., \& Streimikiene, D. (2018). Income inequality and its consequences within the framework of social justice. Problemy Ekorozwoju, 13(2), 131-138.

28. McGillivray, M. (1990). The Human Development Index: Yet Another Redundant Composite Development Indicators. Deakin University.

29. Nastiti, P. K. Y., Atahau, A. D. R., \& Supramono, S. (2019). Working capital management and its influence on profitability and sustainable growth. Business: Theory and Practice, 20, 61-68. https://doi.org/10.3846/btp.2019.06.

30. Parris, T. M., \& Kates, R. W. (2003). Characterizing and measuring sustainable development. Annual Review of Environment and Resources, 28 (13), 1-28.

31. Piorr, A., Ungaro, F., Ciancaglini, A., Happe, K., Sahrbacher, A., Sattler, C., \& Zander, P. (2009). Integrated assessment of future CAP policies: land use changes, spatial patterns and targeting. Environmental Science \& Policy, 12(8), 1122-1136.

32. Priori, H. P. (2003). Environmental policy, agri-environmental indicators and landscape indicators. Agriculture, Ecosystems \& Environment, 98(1), 17-33.

33. Rajnoha, R., \& Lesníková, P. (2016). Strategic Performance Management System and Corporate Sustainability Concept - Specific Parametres in Slovak Enterprises. Journal of Competitiveness, 8 (3), 107-124. https://doi.org/10.7441/joc.2016.03.07

34. Ravetz J. (2004). Integrated assessment for sustainability appraisal in cities and regions. Environmental Impact Assessment Review, 20(1), 31-64.

35. Roseland, M. (2000). Sustainable community development: integrating environmental, economic, and social objectives. Progress in planning, 54(2), 73- 132.

36. Šaparauskas, J. (2004). Darnaus miesto vystymo(si) daugiatiksle selektonovacija. Daktaro disertacija. Vilnius. 
37. Scherp, J. (1994). What does an economist need to know about the environment? Directorate-General for Economic and Financial Affairs. Economic papers of the European Commision. No. 107.

38. Slatmo, E., Fischer, K., \& Roos, E. (2017). The framing of sustainability in sustainability assessment frameworks for agriculture. Sociologia Ruralis, 57(3), 378-395.

39. Smit, B., \& Smithers, J. (1993). Sustainable agriculture: interpretations, analyses and prospects. Canadian Journal of Regional Science, 16(3), 499-524.

40. Sydorovych, O., \& Wossink, A. (2008). The meaning of agricultural sustainability: evidence from a conjoint choice survey. Agricultural Systems, 98(1), 10-20.

41. Thompson, P. B. (2007). Agricultural sustainability: what it is and what it is not. International Journal of Agricultural Sustainability, 5(1), 5-16.

42. Ulewicz, \& R., Blaskova, M. (2018). Sustainable development and knowledge management from the stakeholders' point of view. Polish Journal of Management Studies, 18 (2), 363-374.

43. Volkov, A. (2018). Assessment of the impact of the common agricultural policy direct payments system on agricultural sustainability. Doctoral Dissertation. Vilnius

44. Wass, T., Hugé, J., Block, T., Wright, T., Benitez-Capistros, F., \& Verbruggen, A. (2014). Sustainability assessment and indicators: Tools in a decision-making strategy for sustainable development. Sustainability, 6(9), 5512-5534.

45. Wilson, M. C., \& Wu, J. (2017). The problems of weak sustainability and associated indicators. International Journal of Sustainable Development and World Ecology, 24(1), 44-51.

46. Yoon, S. W., \& Lee, D. K. (2003). The development of the evaluation model of climate changes and air pollution for sustainability of cities in Korea. Landscape and Urban Planning, 63(1), 145-160.

\section{Contact information}

prof. habil. dr. Romualdas Ginevicius

Vilnius Gediminas Technical University

Faculty of Business Management

Dynamic Management Institute

Sauletekio al. 11, LT-10223, Vilnius

Lithuania

E-mail:romualdas.ginevicius@vgtu.lt

ORCID: 0000-0003-2067-4398 